\title{
GRADIÊNCIA E VARIAÇÃO NAS CONSTRUÇÕES DE FOCO NO PORTUGUÊS BRASILEIRO
}

\author{
Maria Luiza Braga \\ Diego Leite de Oliveira \\ Elisiene de Melo Barbosa
}

RESUMO

Caracterizamos e exemplificamos oito diferentes tipos de construçōes clivadas no português brasileiro. Mostramos que as diferenças entre as construçôes, quanto a suas propriedades morfossintáticas, são de ordem quantitativa, o que explicaria sua potencial intercambialidade. Defendemos que algumas delas exibem um grau mais elevado de gramaticalidade e que servem à sinalização de foco em oraçóes simples.

PALAVRAS-CHAVE: construções de foco; português brasileiro; variação e intercambialidade.

s questôes relativas à quantidade/frequência/ocorrência de padróes linguísticos podem ser centrais em certas abordagens e, a título de exemplo, considere-se a sociolinguística variacionista (Labov 1972 ${ }^{1}$ ). De acordo com este modelo, a análise quantitativa requer a criteriosa investigação qualitativa de cada dado empírico, a partir de categorias predeterminadas por hipóteses linguísticas. Cabe às medidas estatísticas a identificação do "peso" de cada fator/cada variável para aplicação de uma regra particular. Tais medidas, permitem, consequentemente, a hierarquização dos fatores e variáveis independentes que motivam a seleção de uma variante.

1 LABOV, William. Sociolinguistic patterns. Philadelphia: University of Philadelphia Press, 1972. 
Nos estudos sobre gramaticalização, consideraçóes relacionadas à frequência também são pertinentes. Para Bybee $(2010)^{2}$, por exemplo, a repetiçẫo é um dos processos caracterizadores da gramaticizaçáo, como se pode verificar no trecho seguinte: "Eu proporei uma nova definição de gramaticização, uma que reconheça o papel crucial da repetiçáo na gramaticizaçáo e que a caracterize como o processo graças ao qual uma sequência frequentemente usada de palavras ou morfemas se torna automatizada como uma única unidade de processamento." (Bybee 2010: 603) ${ }^{3}$. Baseando-se em Haiman (1994), Bybee defende que a repetição leva à ritualização de que decorrem a habituação, a automatização, a redução de forma e a emancipaçáo. Em outras palavras, para Bybee, a natureza da representação cognitiva pode se modificar em função da frequência de uso.

Neste trabalho, voltamo-nos para algumas dessas questóes a partir do exame de um conjunto de construçôes de foco, tais como sáo usadas na variedade carioca do português brasileiro ${ }^{4}$. A coexistência e produtividade de um grande número de padrôes clivados nesta variedade linguística suscitam questôes várias que têm a ver com sua representaçáo, suas correlaçóes com propriedades gramaticais e pragmático-discursivas e a potencial intercambialidade entre elas.

As construções de foco que nos interessam são, usualmente, referidas como construçōes clivadas que, por seu turno, são caracterizadas como uma estrutura complexa formada por duas oraçôes, uma das quais introduzida por um pronome relativo ou palavra $Q U$ e a outra apresentando o verbo ser. A esta estrutura bioracional corresponde uma proposição que poderia ter sido expressa por uma oração simples equivalente, isto é, desprovida da palavra $Q U$

2 BYBEE, Joan. Language, Usage and Cognition. Cambridge: Cambridge University Press, 2010.

3 "I will argue for a new definition of grammaticization, one which recognizes the crucial role of repetition in grammaticization and characterizes it as the process by which a frequently used sequence of words or morphemes becomes automated as single processing unit." (Bybee 2010: 603).

4 Os dados de fala foram coletados na Amostra80, conjunto de 64 horas de gravaçáo e transcrição de fala semicoloquial de cariocas, estratificados segundo as variáveis sociais sexo-gênero, idade, grau de escolaridade. Como todos os dados de fala provêm de uma mesma amostra, seráo fornecidas neste artigo informaçôes apenas sobre o número do falante e seu gênero-sexo. A referida amostra, constituída entre o final da década de 70 e início dos anos 80, integra o acervo do PEUL - Projeto de Estudos sobre o Uso da Língua, sediado na UFRJ. Eventualmente, serấo apresentados dados identificados na internet. As indicaçóes relativas à fonte do dado ocorrem entre parênteses. 
e verbo ser. Estas propriedades são referidas em uma série de caracterizações (Crystal $1985^{5}$, Pavey $2003^{6}$, Hedberg $1988^{7}$, a título de exemplo) e podem ser conferidas em Lambrecht $(2001)^{8}$ :

“Uma CONSTRUÇÃO CLIVADA é uma estrutura complexa que consiste de uma oração matriz introduzida por uma cópula e de uma oração relativa ou tipo relativa cujo argumento relativizado está coindexado ao argumento predicativo da cópula. Consideradas juntas, as oraçóes matriz e relativa expressam uma proposição logicamente simples, que poderia ter sido igualmente expressa sob a forma de uma oração simples sem mudança nas condiçôes de verdade." (LAMBRECHT, 2001, p. 4) ${ }^{9}$

Desde Jespersen (1949, pag. 147, apud LAMBRECHT 2001, pag. $3^{10}$ ), em seu trabalho seminal, as construçôes clivadas tendem a ser associadas à expressão de foco, razão pela qual nos referiremos variavelmente a nosso fenômeno em análise como construções clivadas e construçóes de foco. $\mathrm{O}$ conceito de construção, por seu turno, remete a Goldberg $(1995,2006)^{11}$,

5 CRYSTAL, David. Dicionário de Linguística e Fonética. Rio de Janeiro: Jorge Zahar, 1985.

6 PAVEY, Emma. "An analysis of it-clefts within a Role and Reference Grammar framework". International Conference on Role and Reference Grammar. São José do Rio Preto (SP): UNESP, 2003.

7 HEDBERG, Nancy Á. "The Discourse Functions of Cleft Sentences in Spoken English". Linguistic Society of America, 1988.

8 LAMBRECHT, Knud. "A framework for the analysis of cleft constructions". Linguistics 39.3: 463-516. 2001.

9 A CLEFT CONSTRUCTION is a complex structure consisting of a matrix clause headed by a copula and a relative or relative-like clause whose relativized argument is coindexed with the predicative argument of the copula. Taken together, the matrix and the relative express a logically simple proposition, which can also be expressed in the form of a single clause without a change in the truth conditions." (LAMBRECHT, 2001, p. 4)

10 JESPERSEN, Otto. A modern grammar on historical principles. Part VII, Syntax. Copenhagen, Ejnar Munksgaard, 1949.. Apud Lambrecht, Knud (2001) "A framework for the analysis of cleft constructions”. Linguistics 39.3: 463-516. 2001.

11 GOLDBERG, Adele E. Constructions A Construction Grammar Approach to Argument Structure. Chicago: The University of Chicago Press, 1995.

-__ Constructions at Work. The Nature of Generalization in Language. Oxford: Oxford University Press, 2006. 
Croft (2001) ${ }^{12}$ e Bybee (2010) e é entendido como um pareamento entre forma e significado/função para o qual as questóes atinentes à composicionalidade e esquematicidade são relevantes.

Com respeito ao português brasileiro, a análise de amostras de fala, produzidas em situações não-laboratoriais de comunicação, revela a coexistência de uma grande variedade de construçóes clivadas, algumas das quais se conformando à definição proposta por Lambrecht (2001) e outras dispensando a presença ou do verbo ser ou da palavra $Q U$, ou seja, prescindindo do critério da bioracionalidade.

À primeira vista, estas construçôes poderiam ser distribuídas em duas "subfamílias" (Cf. Braga e Barbosa 2009 ${ }^{13}$ ), uma das quais incluiria as Pseudo-Clivadas, correspondentes às Wh-Clefts do inglês, as Pseudo-Clivadas Invertidas, as Pseudo-Clivadas Extrapostas e, possivelmente, a variante Foco Ser. A outra "subfamília" congregaria as chamadas Clivadas Canônicas, correspondentes às It-Clefts do inglês, as Construçóes Ser Que, as Construções Que e as Construçôes Ser... Ser Que. Esta dispersão de estratégias de focalização, sua gradiência e variação suscitam questóes várias e, neste trabalho, interessam-nos as seguintes:

i. Exibiriam as variadas construçôes de foco os mesmos correlatos gramaticais e pragmático-discursivos, podendo, portanto, ser intercambiadas livremente?

ii. Poderiam as medidas estatísticas constituir critérios confiáveis para se deslindarem as relaçóes entre os membros de cada subfamília?

Este trabalho compreende 3 seçóes. Na primeira, descrevemos, exemplificamos e analisamos as construções de foco segundo algumas variáveis de natureza morfossintática. Na segunda, consideramos a gradiência das Construções Foco Ser. As consideraçóes finais são apresentadas na terceira parte.

12 CROFT, William. Radical construction grammar.Syntactic theory in typological perspective. Oxford: Oxford University Press, 2001.

13 BRAGA, Maria Luiza; BARBOSA, Elisiene de Melo. "Construçôes clivadas no português do Brasil sob uma abordagem funcionalista”. Matraga, v. 16, n. 24:173-196, Rio de Janeiro, 2009. 


\section{Estratégias de focalização no português falado no Brasil}

Com vistas a responder a primeira das questôes norteadoras deste trabalho, descrevemos, exemplificamos e investigamos sete variantes clivadas ${ }^{14}$ segundo a classe de palavras e função sintática do constituinte focalizado e a correlação modo-temporal entre o verbo ser e o predicado verbal da oração subordinada.

1. Construções Pseudo-Clivadas

Quem/O Que Oração sem constituinte clivado Ser Constituinte Clivado (1) F: Quem estava com a chave ora jardineiro. $(18, \mathrm{f})$

2. Construções Pseudo-Clivadas Invertidas

Constituinte Clivado Ser Quem/O Que Or. sem constituinte clivado

(2) F: Esse padre foi quem deixou (o colégio) para a ordem $(26, \mathrm{~m})$

3. Construções Pseudo-Clivadas Extrapostas

Ser Constituinte Clivado Quem/O que SV

(3) F: $E$ ele mesmo quem declama. (Revista

O Globo, 27/01/2013)

4. Construção Foco Ser

Oração sem Constituinte Clivado Ser Constituinte Clivado

(4) F: Todo homem que está ficando velho quer é jogar. $(30, \mathrm{~m})$

5. Construção Clivada Canônica

Ser Constituinte Clivado Que Or. sem constituinte clivado

(5) Fui eu que escrevi. $(43, \mathrm{f})$

6. Construção Ser Que

Constituinte Clivado Ser Que Or. sem constituinte clivado

(6) F: Eles éque uma vez implicaram comigo $(26, \mathrm{~m})$

7. Construção Que

Constituinte Clivado Que Or. sem constituinte clivado

(7) F: Eles que enrolaram $(18, \mathrm{f})$

14 A descrição é baseada em Prince (1978). PRINCE, Ellen. "A comparison of wh-clefts and it-clefts in discourse". Language 54: 883-906, 1978. 
8. Construção Ser... Ser Que

Ser Constituinte Clivado Ser Que Or. Sem constituinte clivado (8) É o homem é que faz ele violento, né? $(22, \mathrm{f})$

Nas construções Pseudo-Clivadas, o constituinte focalizado ocorre à direita do verbo ser, funciona, não marcadamente, como sujeito ${ }^{15}$, expresso por SN de núcleo substantival ou pronominal, e seu referente tende a apresentar os traços [+referencialidade], [+identificabilidade] e [+animacidade]. Em caráter excepcional, verbos ergativos podem ter seu argumento focalizado em uma construção clivada. Para esta variante, a correlação modo-temporal entre o verbo ser e o predicado verbal da oração subordinada é categórica, como pode ser verificado em (9).

(9) F: Tudo aí é uma questão de conversar, entrar num entendimento e dá tudo certo.

E: Hanhan.

F: Mas muita das vezes o que falta é um diálogo $(05, \mathrm{f})$

As Pseudo-Clivadas Invertidas e as Pseudo-Clivadas Extrapostas compartilham com as Pseudo-Clivadas a função sintática e os traços semântico-pragmáticos do referente do constituinte focalizado e a correlação modo-temporal. Também mobilizam uma leitura identificacional, diferindo quanto à posição do constituinte clivado que pode ocorrer ou à direita de ser (Pseudo-Clivada Extraposta) ou a sua esquerda (Pseudo-Clivada Invertida).

\begin{tabular}{|l|l|}
\hline Pseudo-Clivada & Quem estava com a chave era o jardineiro. \\
\hline Pseudo-Clivada Extraposta & $\begin{array}{l}\text { Era eu quem caprichava no sapato da minha } \\
\text { irmá. }\end{array}$ \\
\hline Pseudo-Clivada Invertida & $\begin{array}{l}\text { Esse padre foi quem deixou (o colégio) para } \\
\text { a ordem. }\end{array}$ \\
\hline
\end{tabular}

15 Objetos diretos e circunstanciais também podem preencher a posição de foco das Pseudo-Clivadas. O exemplo seguinte foi coletado na ferramenta de pesquisa Google:

O que eu quero é uma mulher (Canal da Rádio Comercial no You Tube, disponível em: http://www.youtube.com/watch?v=nFAsUIpL8B4) 
Essas três variantes, enquanto estruturas identificacionais, parecem admitir livremente a inversão de seus segmentos constitutivos. As duas últimas são de ocorrência rarefeita e não serão mais referidas.

As Construções Foco Ser compartilham com as Construçóes Pseudo-Clivadas o fato de focalizarem um constituinte que ocorre à direita do verbo ser, frequentemente, o último constituinte da estrutura clivada. Diferem quanto à grande variabilidade de fronteiras de eleitoras nas quais a forma flexionada do verbo ser é inserida: pode ocorrer intercalada entre as partes constitutivas do modal ter que; entre o morfema gramatical $i r$, indicador de tempo-modalidade, e o verbo principal; entre a oração matriz e sua encaixada; antes do objeto direto, predicativo, adjunto, oblíquo, circunstancial, aposto e argumento de verbo ergativo, como se exemplifica a seguir.

(10) F: Tem mais é que ver coisa velha $(16, \mathrm{f})$

(11) F: Vou é viver a vida. (25, m)

(12) F: A gente queria era rever algumas coisas $(41, \mathrm{~m})$

(13) F: Tinha que fazer era mamadeira $(34, \mathrm{f})$

(14) F: Eles ficam é enciumado $(44, \mathrm{f})$

(15) F: Eu vou vender é por quinhentos (cruzeiros) (26, m)

(16) F: Eu gosto mesmo é daqui de Ipanema $(34, \mathrm{f})$

(17) F: Vou é para casa $(05, \mathrm{f})$

(18) F: Apareceu foi a metade do corpo $(03, \mathrm{~m})$

Para a maioria das Construçóes Foco Ser, a questão dos traços [ \pm referencialidade], [ \pm animacidade], e [ \pm identificabilidade] náo se coloca e os poucos SNS focalizados nestas construçóes tendem a apresentar o traço [-especificidade]. Outra diferença, com relação às Construçóes Pseudo-Clivadas, diz 
respeito à correlação modo-temporal que é variável em se tratando de Construçôes Foco Ser: 13,3\% (4/41) dos dados dispensam-na como se exemplifica em (19). Os resultados apresentados até o momento são, portanto, sugestivos de uma potencial descategorização do verbo ser que estaria se cristalizando na $3^{\text {a }}$.pessoa do singular do presente do indicativo, como um marcador invariável de foco. Por outro lado, seu pequeno corpo fônico favorece sua inserção em, praticamente, todas as fronteiras de constituintes e a única restrição diz respeito à posição do sintagma ressaltado, que deve sempre ocorrer a sua direita.

(19) F: Quando o povo não estava é identificado com ele $(41, \mathrm{~m})$

A outra "subfamília", como mencionamos na introdução, é integrada pelas Clivadas Canônicas, Construções Ser Que, Construções Que e Construções Ser...Ser Que. As Clivada Canônicas compartilham com as Pseudo-Clivadas o fato de permitir a focalização de substantivos e pronomes pessoais, empregados, em proporção quase equânime, quer em acepção [+específica], como se ilustra em (20), quer em acepção [-específica], como se exemplifica em (21). Elas divergem, no entanto, por admitirem, na posição focal, uma vasta gama de classe de palavras: demonstrativos em referência estendida (22), dêiticos seja em referência a lugar, tempo ou modo, (23) e de itens utilizados como recurso anafórico (24), fato compatível com o caráter invariável da palavra Que.

(20) F: Mas ela (mãe da falante) não faz vestido de noiva, não, ela faz vestido assim para madrinha, para daminha, para mãe, para irmã, faz para todo mundo, menos para noiva! Não sei, acho que é dela mesmo. Se bem que o vestido dela, foi ela que fez, dela, da minhas tias, ela que fez $(39, \mathrm{f})$

(21) F: ... paulista tá tão preocupado em trabalhar, né? que a gente diz... O carioca goza muito o paulista, né? E diz que ele só sabe trabalhar, né? Vai ver que é ele que talvez tenha mais campo de trabalho, não é mesmo? $(45, \mathrm{~m})$

(22)F: Se der para me formar, tudo bem, né? Se não der eu ir arranjar uma coisa melhor para mim viver minha vida, eu sozinha, sabe? sem ter que morar na casa dos outros. É isso que eu quero $(05, \mathrm{f})$

(23) E: Foi lá que você conheceu a Roseli? $(01, \mathrm{~m})$ 
A alteração de ordem entre oração subordinada e constituinte focalizado é vedada a esse tipo de construção, e a percentagem para a correlação modo-temporal é inferior àquela apresentada pelas Construçôes Foco Ser (3,00\%) $(1 / 55)$.

As diferenças entre os dois outros mecanismos de focalização - Construçôes Ser Que e Construçôes Que - também são de ordem quantitativa. Com elas, podem-se ressaltar $\mathrm{SNs}$ com núcleo pronominal e substantival, associados quer a referentes com leitura [+ específica], conforme se ilustra em (24), quer com leitura [- específica], como se exemplifica em (25), e, principalmente, pronomes demonstrativos com referência estendida, dêiticos, elementos com função anafórica e oraçôes hipotáticas. Quanto à classe de palavras e função sintática do constituinte focalizado, as similaridades entre Clivadas Canônicas, Construçōes Ser Que e Construçôes Que são acentuadas e são sugestivas da maior homogeneidade dessa subfamília.

(24) F: E nós dizemos em Minas que o carioca é que puxa o "s". (27,f)

(25) F: Só eu e o Joãozinho que somos solteiros $(09, \mathrm{~m})$

(26) F: Eu não sei te dizer se agora é que tá certo ou se antes é que era errado, né? $(34, \mathrm{f})$

(27) F: Depois que eu caí na real. $(15, \mathrm{~m})$

(28) F: Ah! Porque eu sou preso, eu fui preso uma vez, eu sou revoltado, vou sair daqui metendo bronca aí que eu vou assaltar mesmo!" $(05, f)$

A palavra QU nas Construçôes Clivadas Canônicas, Construçóes Ser Que e Construçóes Que é insensível ao traço [ \pm animacidade] e sua invariabilidade se coaduna com a focalização de itens dêiticos e anafóricos. Por fim, vale lembrar que os segmentos constitutivos da estrutura clivada náo podem ter a ordem alterada, como se pode verificar na construçáo a seguir:

(29a) F: Fui eu que escrevi. $(43, \mathrm{f})$

(29b)? Que escrevi fui eu. 
No que tange à correlação modo temporal, as Construções Ser Que exibem um mais alto grau de fixidez do que as construçóes Clivadas Canônicas e Foco Ser: enquanto nas duas últimas estruturas o verbo ser ainda se mostra variavelmente sensível ao modo-tempo do verbo da oração introduzida pela palavra QU, nas primeiras ele se encontra relativamente descategorizado, isto é, na amostra em exame, ocorre sempre na $3^{a}$ pessoa do singular, presente do indicativo, independentemente do tempo-modo do outro verbo, como se exemplifica em (30). Em outros corpora, todavia, podem ser identificadas ocorrências com o verbo ser em tempos verbais diferentes do presente do indicativo, como se exemplifica em (30b)

(30) F: Esse braço é que quebrou um pouquinho $(18, \mathrm{f})$

(30b) $\boldsymbol{O}$ homem foi que chamou a polícia. (Portal Cantu)

Uma outra evidência a favor da hipótese que concebe a Construção Ser Que como descategorizada é fornecida pela ausência de concordância número-pessoal com o constituinte focalizado, como se verifica em (31)

(31) F: Nós é que vamos ser prejudicado. (07, m)

As questôes suscitadas a propósito das Construções Ser Que não se colocam para as Construções Que, já que elas dispensam o verbo ser. A questão é de outra natureza e remete à própria concepção de estrutura clivada: uma vez que a palavra QUE, à semelhança de ser nas Construçóes Foco Ser, funciona apenas como um marcador de foco, poderiam estas estruturas ser caracterizadas como clivadas?

Por fim, vale ressaltar que as Construções Ser... Ser Que se comportam como os demais membros desta subfamília. Através dela se focalizam SNs, na função de sujeito, e dêiticos. Dada sua baixa frequência, não serão consideradas daqui para frente.

Como mostramos até o momento, a identificação de cada padrão estrutural não é problemática. A gradiência e variação se manifestam de acordo com suas propriedades gramaticais, como pode ser verificado nas representaçóes gráficas que são mostradas a seguir: 


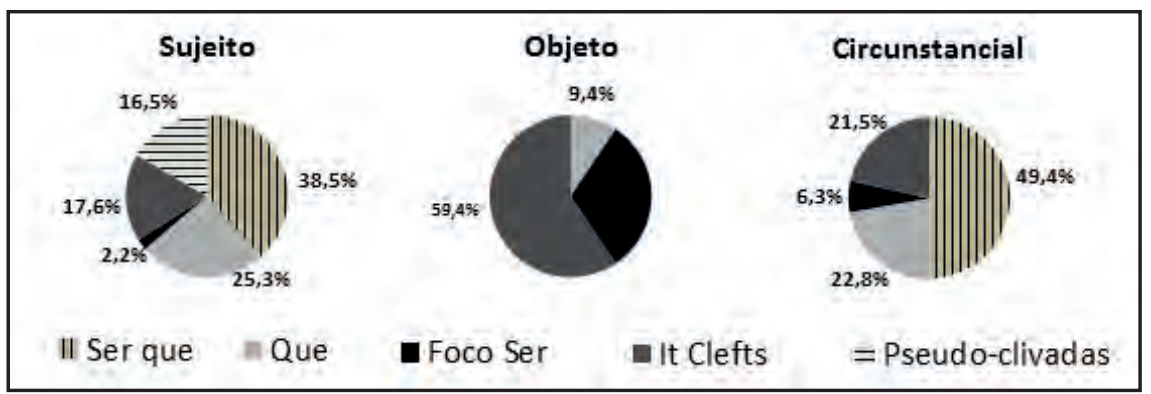

Figura 1: Função sintática dos constituintes clivados

Os gráficos acima revelam que os sujeitos, os objetos diretos e os circunstanciais podem, em principio, ser focalizados pelas diferentes estratégias clivadas. Há, porém, diferenças estatísticas interessantes entre esses vários tipos: Ser que, por exemplo, associa-se mais frequentemente à focalização de sujeitos e circunstanciais; as Clivadas Canônicas, por seu turno, são mais utilizadas quando da focalização de objetos diretos. No que tange aos sujeitos, as diferenças percentuais entre Pseudo-Clivadas e Construçóes Que são pequenas. Constatação similar pode ser verificada a propósito da focalização de circunstanciais por Clivadas Canônicas e Construçóes Que.

Os gráficos relativos às classes de palavras dos constituintes focalizados são mostrados a seguir:

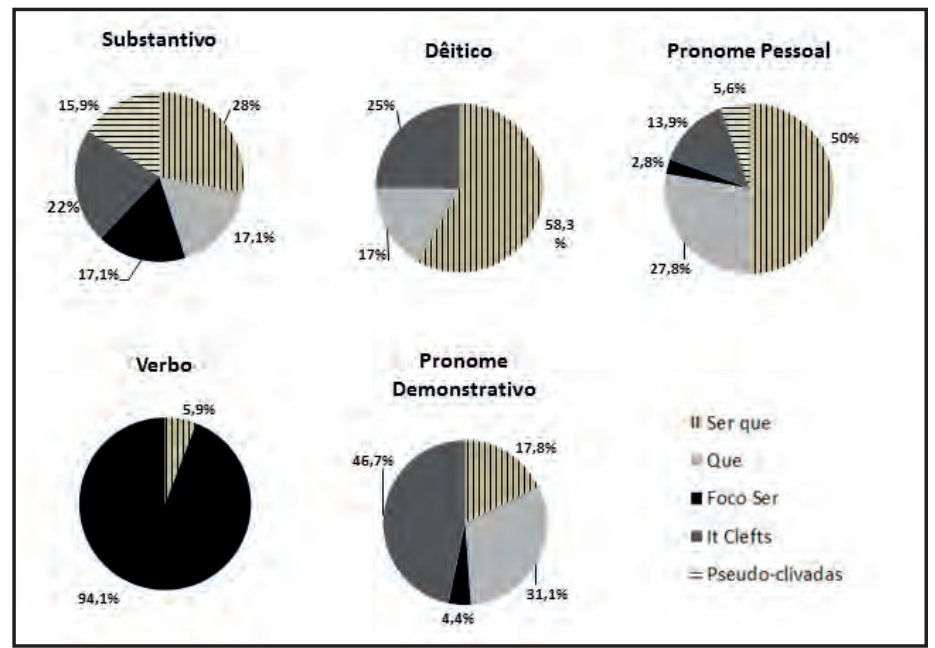

Figura 1. Civadas e classes de palavras. 
Os gráficos acima mostram que os substantivos, potencialmente, são focalizados pelos variados mecanismos de clivagem e que as diferenças percentuais entre eles não são acentuadas. Os dêiticos são ressaltados, não marcadamente, por Construçôes Ser Que, e, com frequência mais restrita, pelas Clivadas Canônicas e Construçôes Que. Os Pronomes pessoais são salientados, mais amiudadamente, por Construçôes Ser Que; mas podem sê-lo, também, pelas Construçóes Que e, mais raramente, pelas outras estratégias. Os verbos exibem menor variação, visto que sua focalização por meio de outra construção diferente de Foco Ser é esporádica. Os pronomes demonstrativos, por seu turno, tendem as ser ressaltados por Clivadas Canônicas e, em proporção menor, também por Construçóes Que e Construçôes Ser Que. Sua focalização por meio de Construçóes Foco Ser é esporádica.

A variação salientada ao longo deste trabalho parece constitutiva das construçóes estudadas, o que justificaria a potencial intercambialidade entre elas. O exame de dados empíricos, inclusive, mostra como um mesmo falante, quase sequencialmente, pode parafrasear um conteúdo proposicional usando construçóes diferentes, conforme exemplifica o trecho seguinte:

(32) F: O rombo é muito grande. O rombo está muito grande. Então para eles tentar fechar, quem sofre é a gente, rapaz! É a gente é que sofre. Gasolina subindo todo dia! todo dia a gasolina sobe, agora! $(25, \mathrm{~m})$

Ao destacar um constituinte por meio de marcas prosódicas e morfológicas, as construções em estudo fazem emergir uma nuance contrastiva, ausente da contrapartida náo clivada. Embora em termos proposicionais possa se pensar até em uma equivalência entre estruturas clivadas e não clivadas, o valor retórico e os correlatos pragmático-discursivos das primeiras são singulares.

\section{O estatuto das construções foco ser}

Os padrōes estruturais considerados na primeira seção deste trabalho se caracterizam, segundo a proposta de Traugott $(2009)^{16}$, como microconstruçôes que, por sua vez, se organizam em duas mesoconstruçóes, aquela integra-

16 TRAUGOTT, Elizabeth Closs. "Grammaticalization and Construction Grammar". In CASTILHO, Ataliba Teixeira (Org.) História do Português Paulista. Série Estudos, vol. I. Campinas: Unicamp/Publicações IEL, 2009. 
da pelas Clivadas Canônicas, Construçóes Ser Que, Construçóes Que, Construçōes Ser... Ser Que, por um lado, e aquela formada pelas Pseudo-Clivadas, Pseudo-Clivadas Invertidas, Pseudo-Clivadas Extrapostas, por outro lado. Elas coexistem com outras estratégias linguísticas às quais também tem sido atribuída a função de foco, como é o caso das chamadas Construções Foi Fez, atualmente rotuladas de paratáticas e examinadas, entre outros, por Rodrigues $(2006)^{17}$ e Coelho $(2013)^{18}$, e também as oraçôes desgarradas, investigadas por Decat $(2005)^{19}$. Esse rol de mecanismos estruturalmente distinto constitui a Macro Construção de Foco.

As construçôes objeto de nosso estudo são visceralmente variáveis, pelo menos no que tange às propriedades morfossintáticas investigadas - classe de palavras e função sintática do constituinte focalizado e correlação modo-temporal entre o verbo ser e o verbo da oração subordinada -, e sua melhor categorização se faz pela teoria dos protótipos.

Embora as questóes relativas à gradiência (Bybee 2010) não representem uma dificuldade para a identificação de cada estratégia particular de focalização, a afiliação das Construçóes Foco Ser a uma das duas mesoconstruçóes que propusemos é delicada. Esse mecanismo de focalização compartilha com as Pseudo-Clivadas o fato de ressaltar constituintes que ocorrem à direita do verbo ser e, possivelmente, essa é a razão pela qual elas podem ser aproximadas. Todavia, como mostramos previamente, os dois tipos de padrão divergem quase frontalmente quanto às demais variáveis e parece-nos mais adequado considerar as Construçôes Foco Ser em sua especificidade.

As construçôes, como lembra Goldberg (1995), se submetem aos mesmos princípios que organizam as demais unidades linguísticas e, enquanto tal,devem contrair relaçôes entre si. Em outras palavras, já que quase todas as estruturas clivadas analisadas aqui requerem a presença do verbo ser, usualmente na $3^{\text {a }}$ pessoa do singular, presente do indicativo, as relações entre elas e a Construção Foco Ser devem ser recíprocas e multilaterais.

17 RODRIGUES, Angélica Terezinha "Eu fui e fiz esta tese": As construções do tipo foi fez no Português do Brasil. Tese de doutorado. Campinas: Unicamp, 2006.

18 COELHO, Carolina Medeiros. Construçóes com o verbo agarrar em Português Brasileiro e Europeu. Dissertação de Mestrado. Uberlândia: UFU, 2013.

19 DECAT, M. B. N. “Oraçôes relativas apositivas: SN 'soltos' como estratégia de focalização e argumentação”. Veredas, v.8, n.1 e 2: 79-101. Juiz de Fora (MG): Editora UFJF, 2005. 
Outra questão, muito mais especulativa, concerne ao potencial efeito de outras construçóes que, embora não estejam associadas a foco, valem-se do verbo ser, como é o caso do "é confirmativo" (Lopes 2013) ${ }^{20}$ no contexto de pergunta sim/não e das chamadas oraçóes subordinadas subjetivas. Embora nesses contextos o verbo ser, em princípio, possa ser utilizado em qualquer tempo e modo verbais, nas amostras de fala em estudo, ele é predominantemente usado na $3^{\text {a }}$ pessoa do singular do presente do indicativo. Esse emprego náo marcado poderia estar repercutindo no uso das Construçôes Foco Ser?

\title{
Considerações Finais
}

Neste trabalho, consideramos um conjunto de estruturas associadas à sinalização de foco. Elas se caracterizam como legítimas construçóes, na acepção defendida por Goldberg (1995), vale dizer, atendem ao requisito de não composicionalidade. As construçôes examinadas são visceralmente gradientes e variáveis no que concerne a suas propriedades morfossintáticas, e as diferenças entre elas são de ordem quantitativa, o que explicaria sua potencial intercambialidade. Defendemos que as Construçóes Ser Que, Construçóes Que e Construçóes Foco Ser exibem um grau mais elevado de gramaticalidade e que servem à sinalização de foco em oraçóes simples.

\section{GRADIENCE AND VARIATION IN FOCUS CONSTRUCTIONS IN BRAZILIAN PORTUGUESE}

\begin{abstract}
In this paper we exemplify and analyze eight different types of cleft constructions in Brazilian Portuguese. We show that the differences among the constructions, with regard to their morphosyntactic properties, are quantitative, which explains their potential mutual interchangeability. We show that some of the constructions dis-
\end{abstract}

20 LOPES, Quézia dos Santos. O item “É Confirmativo” em Contexto de Pergunta Sim/Não. Dissertação de Mestrado. Rio de Janeiro: UFRJ, 2013. 
play a higher degree of grammaticalization and function as focus marker in simple clauses.

KEY WORDS: focus constructions; Brazilian Portuguese; variation and interchangeability.

Recebido em: 11/12/2012

Aprovado em: 05/08/2013 